\title{
Commentary: Moving the guidelines for mitral repair
}

\author{
Paul Kurlansky, MD
}

\author{
From the Division of Cardiac Surgery, Department of Surgery, Columbia University, New York, NY. \\ Disclosures: Author has nothing to disclose with regard to commercial support. \\ Received for publication Jan 15, 2019; accepted for publication Jan 15, 2019; available ahead of print April 13 , \\ 2019. \\ Address for reprints: Paul Kurlansky, MD, Division of Cardiac Surgery, Columbia University, Black Building \\ 210, 650 W 168th St, New York, NY 10032 (E-mail: pk2245@cumc.columbia.edu). \\ J Thorac Cardiovasc Surg 2019;158:97-8 \\ $0022-5223 / \$ 36.00$ \\ Copyright (c) 2019 by The American Association for Thoracic Surgery \\ https://doi.org/10.1016/j.jtcvs.2019.01.144
}

Both European ${ }^{1}$ and American ${ }^{2}$ guidelines currently recommend percutaneous mitral repair as a "weak" class IIb recommendation that "may be considered" for patients with symptomatic, severe primary mitral regurgitation who are judged by a Heart Team not to be surgical candidates. However, given increasing facility with percutaneous techniques, likely technological advances, and compelling clinical need in an aging population, indications are likely to expand. Careful analysis of clinical experience is an essential complement to the criterion standard of the randomized clinical trial and is frequently the source helpful findings that can drive future research. The report of Buzzatti and colleagues $^{3}$ in this issue of the Journal provides just such valuable information. Challenging the findings of the landmark Endovascular Edge-to-Edge Repair Study (EVEREST) II trial, which found no benefit for either surgical or percutaneous treatment of severe mitral regurgitation in the predefined subset of patients older than 75 years, ${ }^{4}$ Buzzatti and colleagues ${ }^{3}$ reviewed their 12-year clinical experience with patients 75 years old and older who underwent either percutaneous repair with MitraClip (Abbott Vascular, Santa Clara, Calif) or surgical repair for severe primary degenerative mitral regurgitation. Patients were at low to moderate surgical risk: STS predicted risk of mortality (PROM) median values were $1.64 \%$ (interquartile range, 1.30-2.41) in the surgical group and 2.99 (interquartile range, 2.29-4.38) in the MitraClip group (all $<8 \%$ ). Although there may have been a learning curve, procedural success appears appropriate, with only $3.2 \%$ of surgical patients and $6.9 \%$ of patients in the MitraClip group having conversion to replacement and only $2.8 \%$ of surgical patients and $27 \%$ of those in the MitraClip group having at least $2+$ postprocedural regurgitation $(23 \%$ of EVEREST II patients had $3+$ to $4+$ regurgitation before hospital discharge after clip placement). As might be expected, the groups were clinically distinct, with a higher incidence of comorbidities and higher STS PROM in the MitraClip group $(P<.001)$. Propensity score modeling was the basis for inverse probability of treatment weighting to account for differences in patient selection. Interestingly, even before inverse probability of treatment weighting, groups were

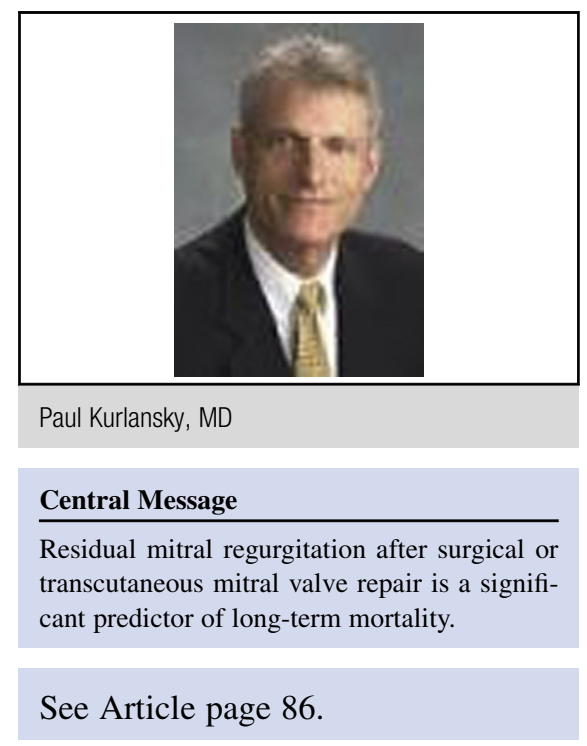

well balanced with regard to many physiologic parameters of mitral regurgitation; however, considerable imbalance between the groups remained even after weighting, with standardized mean difference values that ideally would fall under $10 \%$ ranging between $10 \%$ to $20 \%$ for many clinical factors, including the median STS PROM (1.91 vs 2.48; standardized mean difference, $12 \%$ ). It is therefore not surprising that, unlike the EVEREST II trial, which found no difference in mortality, ${ }^{5}$ this study reports a marked difference in 5-year survival favoring surgery (34.5\% vs $82.2 \%$; hazard ratio, $4.12 ; 95 \%$ confidence interval, $2.31-7.34 ; P<.001)$.

As perhaps expected, STS PROM was an independent risk factor for mortality. What is novel, however, is the question-which was not considered by the EVEREST II investigators - that these surgeons asked: What was the impact of recurrent mitral regurgitation of at least $3+$ on long-term survival? The answer is important. Weighted Cox regression found a hazard ratio of $2.19(P=.033)$. Despite the many limitations of the study, which are well delineated and admirably modeled by Buzzatti and colleagues, ${ }^{3}$ the message is clear: In the elderly population, whatever approach is chosen, the result of the intervention must provide durable relief from severe mitral regurgitation to warrant interventional risk.

\section{References}

1. Baumgartner H, Falk V, Bax JJ, De Bonis M, Hamm C, Holm PJ, et al; ESC Scientific Document Group. 2017 ESC/EACTS guidelines for the management of valvular heart disease. Eur Heart J. 2017;38:2739-91. 
2. Nishimura RA, Otto CM, Bonow RO, Carabello BA, Erwin JP III, Fleisher LA, et al. 2017 AHA/ACC focused update of the 2014 AHA/ ACC guideline for the management of patients with valvular heart disease: a report of the American College of Cardiology/American Heart Association task force on clinical practice guidelines. J Am Coll Cardiol. 2017;70: 252-89.

3. Buzzatti N, Van Hemelrijck M, Denti P, Ruggeri S, Schiavi D, Scarfò IS, et al. Transcatheter or surgical repair for degenerative mitral regurgitation in the elderly: a propensity-weighted analysis. J Thorac Cardiovasc Surg. 2019;158: 86-94.e1.

4. Feldman T, Foster E, Glower DD, Kar S, Rinaldi MJ, Fail PS, et al; EVEREST II Investigators. Percutaneous repair or surgery for mitral regurgitation. $N$ Engl J Med. 2011;364:1395-406. Erratum in: N Engl J Med. 2011;365:189.

5. Feldman T, Kar S, Elmariah S, Smart SC, Trento A, Siegel RJ, et al; EVEREST II Investigators. Randomized comparison of percutaneous repair and surgery for mitral regurgitation: 5-year results of EVEREST II. J Am Coll Cardiol. 2015;66:2844-54. 